\title{
Reasons to be cheerful? Reflections on GPs' responses to depression
}

The papers related to depression in this issue of the Journal offer reasons to be cheerful about GPs' diagnostic abilities and treatment decisions: but they also generate internal debate, and require further reflection.

The perennial question of whether GPs are competent at diagnosing depression receives an affirmative response from the study in the Grampian region of Scotland undertaken by Cameron et al. ${ }^{1}$ This study confirms previous research from Hampshire and elsewhere that GPs are more likely to make a diagnosis of depression as symptom severity increases. ${ }^{2}$ The assessment of depression in primary care is increasingly supported by the use of patient self-completion severity rating instruments, but care is needed in how to interpret them. The Swedish study by Hansson et $a /^{3}$ corroborates earlier analyses identifying diagnostic discrepancies between the Hospital Anxiety and Depression Scale and the Patient Health Questionnaire (PHQ-9), ${ }^{4}$ and shows that the currently recommended threshold score of 10 on the latter is more likely to lead clinicians to diagnose major depression. They support recent research in England, which calls for an increase in PHQ9 threshold score from 10 to 12 for major depression in order to reduce the risk of

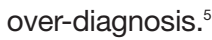

We may therefore assume from these studies that GPs' diagnostic abilities are already in reasonable shape, and could be improved by judicious use of severity rating instruments. However there are important caveats to such an assumption. A focus on symptom counts, which has been encouraged in the UK by the introduction of performance targets for GPs linked to the measurement of depression severity at initiation of treatment, ${ }^{6}$ may well be necessary: but it is far from sufficient. As with other conditions where diagnosis is made on the basis of inevitably arbitrary cut-off points on scoring systems (such as anaemia, asthma, and diabetes), we also need to consider the context of symptoms, and understand the complexity of the relationship between psychological, physical, and social problems and their temporal variations. ${ }^{?}$

The updated NICE guidelines on depression note that identification of major depression should be based not only on its severity but also on persistence, the presence of other symptoms, and the degree of functional and social impairment. ${ }^{8}$ Many people with sub-threshold disorders in current classification systems experience significant degrees of disability, while people with severe depressive symptoms may be able to function with a remarkable degree of normality. ${ }^{9} \mathrm{~A}$ tailored assessment of disability, such as the Social Functioning Questionnaire ${ }^{10}$ could usefully be linked with routine diagnostic systems within primary care.

To address the gaps in our social and cultural understanding of patients' problems, we can turn to the International Classification of Primary Care, ${ }^{11}$ which provides useful methods for recording details of social context, or to the Cultural Awareness Tool, developed for GPs in Australia. $^{12}$ Our awareness of patients' values may be enhanced, for example, by the seven-item spiritual symptom scale in the awkwardly-named but potentially useful Biopsychosociospiritual Inventory. ${ }^{13}$ Such instruments are likely to be of use to researchers in this field, encouraging us to think more widely about the problems being presented. They may sometimes help the busy clinician, as long as their deployment does not interrupt the flow of the consultation. In any event, we should pay careful attention to our patients' perspectives on what may be causing their problems, not least because these may be radically different from our own.

Although patients may sometimes have clear and consistent explanatory models, they are more likely - particularly when seeking help for the first time - to hold beliefs about the cause of their mental health problems which are tentative and fluid, sometimes internally contradictory, and characterised by uncertainty. As
Williams and Healy put it, they may be working from an exploratory 'map of possibilities, which provides a framework for the ongoing process of making sense and seeking meaning'. ${ }^{14}$

The mainstays of GPs' management of depression are prescription of antidepressant medication and referral for psychological therapy. Two papers in this issue indicate that GPs are performing these tasks reasonably well. Cameron et al conclude that GPs in Scotland make circumspect and conservative prescribing decisions, with a tendency to under-use rather than over-prescribe antidepressant medication. ${ }^{1}$ In the qualitative enquiry by Stavrou et al, GPs from London gave accounts of their rational decision making about referral for psychological therapy, exercising their ability to take into account patient expectations of and capacity for therapy, and the extent and limitations of their own capacity to help. ${ }^{15}$

Cameron et al's comments about the under-use of antidepressant medication are part of an ongoing debate within Scotland in response to central guidance that rates of antidepressant prescribing should be reduced. They should be viewed with caution, in the light of mounting evidence of the substantial and increasing placebo effects of antidepressant medication, except perhaps at the very severe end of the symptom spectrum. ${ }^{16,17}$ They also run counter to the views of the Scottish GPs interviewed by Macdonald et al, ${ }^{18}$ who raise substantive concerns about the appropriateness of current levels of prescribing, and are troubled by their involvement in the medicalisation of unhappiness, and their pharmacological responses to problems generated by social deprivation and the breakdown of traditional social and family structures. These doctors also disagree with Stavrou et al's conclusions about rational decision making, seeing themselves as responders to rather than facilitators of change. It is not only GPs who are concerned about their limited and potentially damaging responses to suffering 
and distress; patients are also aware of the moral dilemmas created by accepting a diagnosis of depression and a prescription for antidepressant medication, especially the effects on the sense of self as an autonomous agent. ${ }^{19}$

We need to expand our repertoire of responses. Collaborative models of care, in which practice is restructured to provide adequate follow-up, access to evidencebased expert systems, and strong support for patient self-management have been demonstrably successful in improving patient outcomes..$^{20}$ This may be because they bring with them a sense of security and purpose, often conspicuously lacking in patients who feel low in mood, hopeless and without motivation, and whose poor self-esteem may lead them to worry about bothering the doctor with their concerns. ${ }^{21}$

However, there is severe inequity of access to high-quality mental health services that do exist within primary care. Many people with high levels of mental distress are disadvantaged, either because they are unable to access care (for example, people from black and minority ethnic communities), or because the care they receive does not address their needs (for example, many older people, or those with medically unexplained symptoms). It is not clear whether the new cadres of mental health workers entering primary care will help to resolve this problem, or by swapping psychology for pharmacology we will merely serve to entrench prevailing views of depression as a disease which can only be cured with professional intervention. The AMP research group (Improving Access to Mental Health in Primary Care) is testing a new multifaceted model of care designed to improve access, based on three interlinked components: community engagement, primary care development, and sensitised psychosocial interventions. ${ }^{22}$

In many of the presentations currently labelled as depression, there is sufficient uncertainty about diagnosis and management to allow alternative approaches to be considered. My preference is to move away from the concept of depression as a disease, and to focus instead on the alleviation of suffering ${ }^{23}$ that is experienced and understood by the patient. I consider that this necessitates a re-vision of patients, not as passive victims of disease or circumstance but as active agents, experts in leading their lives, who occasionally need help, new ways of looking at old ideas, and the encouragement of hope. ${ }^{24}$ These perspectives derive ultimately from the wisdom traditions, ${ }^{25,26}$ and are closely related to the emerging constructs of interpretative medicine, which propose that professional knowledge be used 'to support the creative capacity of individuals in maintaining their daily lives. ${ }^{27}$ They invite us to venture from the shelter of diagnoses and interventions of uncertain benefit, and expose ourselves to the raw experience of human suffering, while retaining our belief in patients as persons capable of fulfilling lives.

\section{Christopher Dowrick}

Professor of Primary Medical Care, University of Liverpool, School of Community and Behavioural Sciences, Liverpool.

\section{Provenance}

Commissioned; peer reviewed.

\section{REFERENCES}

1. Cameron I, Reid I, Lawton K. Appropriateness of antidepressant prescribing: an observational study in a Scottish primary-care setting. Br J Gen Pract 2009: 59(566): 644-649.

2. Thompson C, Ostler K, Peveler RC, et al. Dimensional perspective on the recognition of depressive symptoms in primary care: The Hampshire Depression Project 3. Br J Psychiatry 2001; 179: 317-323.

3. Hansson M, Chotai J, Nordstöm A, Bodlund O. Comparison of two self-rating scales to detect depression: HADS and PHQ-9. Br J Gen Pract 2009; DOI: 10.3399/bjgp09X454070

4. Cameron IM, Crawford JR, Lawton K, Reid IC Psychometric comparison of PHQ-9 and HADS for measuring depression severity in primary care. Br J Gen Pract 2008; 58(546): 32-36.

5. Kendrick T, Dowrick C, McBride A, et al. Management of depression in UK general practice in relation to scores on depression severity questionnaires: analysis of medical record data. BMJ 2009; 338: b750. DOI: 10.1136/bmj.b750

6. British Medical Association, NHS Employers. Revision to the GMS contract 2006/07. Delivering investment in general practice. London: Department of Health, 2006.

7. Gask L, Klinkman M, Fortes S, Dowrick C. Capturing complexity: the case for a new classification system for mental disorders in primary care. Eur Psychiatry 2008 ; 23(7): 469-476

8. National Institute for Health and Clinical Excellence. Depression: the treatment and management of depression in adults (update): in press.

9. Foley DL, Neale MC, Gardner CO, et al. Major depression and associated impairment: same or different genetic and environmental risk factors? $A m \mathrm{~J}$ Psychiatry 2003; 160; 2128-2133.

10. Tyrer P, Nur U, Crawford M, et al. The Social Functioning Questionnaire: a rapid and robust measure of perceived functioning. Int J Soc Psychiatry 2005; 51(3): 265-275.

11. Lamberts H, Hofmans-Okkes IM. Classification of psychological and social problems in general practice. Huisarts Wet 1993; 36: 5-13.

12. Seah E, Tilbury F, Wright B, et al. Cultural awareness tool. Perth, Australia: Transcultural Psychiatry Unit, Curtin University and the Royal Australian College of General Practitioners WA Research Unit, 2001.

13. Katerndahl DA. Impact of spiritual symptoms and their interactions on health services and life satisfaction. Ann Fam Med 2008; 6(5): 412-420.

14. William B, Healy D. Perceptions of illness causation among new referrals to a community mental health team: 'explanatory model' or 'exploratory map'? Soc Sci Med 2001; 53(4): 465-476.

15. Stavrou S, Cape J, Barker C. Decisions about referrals for psychological therapies: a matched-patient qualitative study. Br J Gen Pract 2009; DOI: 10.3399/bjgp09X454089

16. Walsh BT, Seidman SN, Sysko R, Gould M. Placebo response in studies of major depression: variable, substantial, and growing. JAMA 2002; 287(14): 1840-1847.

17. Kirsch I, Deacon BJ, Huedo-Medina TB, et al. Initial severity and antidepressant benefits: a meta-analysis of data submitted to the Food and Drug Administration. PLoS Medicine 2008; 5(2): e45.

18. Macdonald S, Morrison J, Maxwell M, et al. 'A coal face option': GPs' perspectives on the rise in antidepressant prescribing. Br J Gen Pract 2009; DOI: 10.3399/bjgp09X454106.

19. Maxwell M. Women's and doctors' accounts of their experiences of depression in primary care: the influence of social and moral reasoning on patients' and doctors' decisions. Chronic Illn 2005; 1(1): 61-71.

20. Gilbody S, Bower P, Fletcher J, Richards D, Sutton AJ. Collaborative care for depression: a cumulative metaanalysis and review of longer-term outcomes. Arch Intern Med 2006; 166(21): 2314-2321.

21. Gask L, Rogers A, Oliver D, et al. Qualitative study of patients' perceptions of the quality of care for depression in general practice. Br J Gen Pract 2003; 53(489): 278-283.

22. University of Liverpool. AMP (Improving Access to Mental Health in Primary Care). Liverpool: University of Liverpool. http://www.liv.ac.uk/amp/ (accessed 13 Aug 2009).

23. Cassel EJ. The nature of suffering and the goals of medicine. NEJM 1982; 306(11): 639-645.

24. Dowrick C. Beyond depression: a new approach to understanding and management. 2nd edn. Oxford: Oxford University Press, 2009.

25. McWhinney I. Being a general practitioner: what it means. Eur J Gen Pract 2000; 6: 135-139.

26. Epstein RM. Mindful practice. JAMA 1999; 282(9): 833-839.

27. Reeve J. Interpretative medicine. Occas Pap R Coll Gen Pract 2009; 88. In press.

DOI: 10.3399/bjgp09X454025

\section{ADDRESS FOR CORRESPONDENCE}

\section{Christopher Dowrick}

University of Liverpool, School of

Community and Behavioural Sciences,

Whelan Building, Liverpool, L69 3GB.

E-mail: cfd@liverpool.ac.uk 